\title{
A Naphthalenediimide-Based Metal-Organic Framework and Thin Film Exhibiting Photochromic and Electrochromic Properties
}

\author{
Yi-Xin Xie, ${ }^{\dagger}$ Wen-Na Zhao, ${ }^{*, \downarrow}$ Guo-Chang Li, ${ }^{\dagger}$ Peng-Fei Liu, ${ }^{\dagger}$ Lei Han ${ }^{*},, \$$ \\ †Institute of Inorganic Materials, School of Materials Science \& Chemical Engineering, Ningbo \\ University, Ningbo, Zhejiang 315211, China \\ Key Laboratory for Molecular Design and Nutrition Engineering of Ningbo, Ningbo Institute of \\ Technology, Zhejiang University, Ningbo, Zhejiang 315100, China \\ ${ }^{\S}$ Key Laboratory of Photoelectric Materials and Devices of Zhejiang Province, Ningbo University, \\ Ningbo, Zhejiang 315211, China \\ Corresponding Author \\ * hanlei@nbu.edu.cn; wnzhao@nit.zju.edu.cn
}

\section{Syhthesis of ligand NDI-ATZ}

To a stirred mixture of 1,4,5,8-Naphthalenetetracarboxylic dianhydride (1.3409 g, 5 mmol), 5-Aminotetrazole monohydrate $(1.0328 \mathrm{~g}, \quad 10 \mathrm{mmol})$ and $\mathrm{N}, \mathrm{N}$-dimethylformamide $(40 \mathrm{~mL})$ in an oil bath was heated to $140{ }^{\circ} \mathrm{C}$. At this temperature, the resulting solution were refluxed $10 \mathrm{~h}$. Then, the reaction mixture was cooled to room temperature, and poured into ice water $(40 \mathrm{~mL})$. The pale yellow solid was collected by filtration and dried in vacuo to yield NDI-ATZ (1.3789 g, 68.6\%). ${ }^{1} \mathrm{H}$ NMR $\left(400 \mathrm{MHz}, \mathrm{DMSO}-\mathrm{d}_{6}, 25^{\circ} \mathrm{C}\right): 8.786(\mathrm{~s}, 6 \mathrm{H}, \mathrm{NH}$ and $\mathrm{C}=\mathrm{CH}), 2.508(\mathrm{~s}, 6 \mathrm{H}$, $2 \mathrm{CH}_{3}$ ). FT-IR $\left(\mathrm{KBr}, \mathrm{cm}^{-1}\right): 3417.30$ (tetrazole $\left.\mathrm{NH}\right), 3079.81$ (aromatic $\left.\mathrm{CH}\right), 1693.22$ (imide $\mathrm{C}=\mathrm{O}$ stretching), 1585.22 ( $\mathrm{NH}$ bending), 838.90 (tetrazole, $\mathrm{N}-\mathrm{N}$ stretching). 


\section{Synthesis of compound NBU-3}

The mixture of $\mathrm{Zn}\left(\mathrm{NO}_{3}\right)_{2} \cdot 6 \mathrm{H}_{2} \mathrm{O}(0.0645 \mathrm{~g}, 0.22 \mathrm{mmol})$, NDI-ATZ (0.0402 g, 0.1 mmol) were dissolved in $\mathrm{N}, \mathrm{N}$-dimethylformamide $(3 \mathrm{~mL})$. Then, the resulting solution were sealed in a stainless-steel tube with a Teflon liner and heated at $80{ }^{\circ} \mathrm{C}$ for 3 days. The yield of is ca. $61 \%$. Anal. Calcd. for $\mathrm{C}_{22} \mathrm{H}_{18} \mathrm{~N}_{12} \mathrm{O}_{6} \mathrm{Zn}(\%)$ : C 43.19, $\mathrm{H}$ 2.97, N 27.47; found (\%): C 43.12, H 3.06, N 27.54. IR (KBr, $\left.\mathrm{cm}^{-1}\right): 3417.30(\mathrm{~m})$, 1695.15 (vs), 1492.66 (s), 1336.45 (vs), 1245.81 (s), 1108.89 (w), 987.39 (w), 838.90 (s), $765.61(\mathrm{~s}), 703.90(\mathrm{w}), 588.19(\mathrm{w})$.

\section{Synthesis of NBU-3 thin films on FTO}

$\mathrm{Zn}\left(\mathrm{NO}_{3}\right)_{2} \cdot 6 \mathrm{H}_{2} \mathrm{O}(0.0645 \mathrm{~g}, 0.22 \mathrm{mmol})$, NDI-ATZ $(0.0402 \mathrm{~g}, 0.1 \mathrm{mmol})$ were dissolved in DMF (60 mL) in a $150 \mathrm{~mL}$ three neck flask. Precleaned FTO substrates (up to 6) were vertically submerged in the solution. The vessel was submerged in an oil heating bath, slowly heated $(\sim 30 \mathrm{~min})$ to $80{ }^{\circ} \mathrm{C}$ under a nitrogen atmosphere, and held at this temperature for $4 \mathrm{~h}$. After allowing the reaction to cool to room temperature, the substrates were removed and briefly washed with acetone to remove loose powder. They were then submerged in a vial containing DMF $(20 \mathrm{~mL})$ and sonicated for $\sim 1 \mathrm{~min}$. After sonication, the films were thoroughly washed with acetone to remove any remaining powder. Prior to spectroelectrochemical measurements, the films attached to the non-conductive surface of the FTO plates were carefully removed by wiping the surface with a Q-tip wetted with $1 \mathrm{M} \mathrm{HCl}$ solution and subsequently wash with ethanol and acetone. 


\section{Experimental Section}

Elemental analyses were carried out on an Elementar Vario EL III analyzer. ${ }^{1} \mathrm{H}$ NMR analyses were carried out on a Bruker BioSpin GmbH analyzer. The FT-IR spectra were recorded from $\mathrm{KBr}$ pellets in the range $4000-400 \mathrm{~cm}^{-1}$ on a Nicolet 6700 spectrometer. Powder X-ray diffraction patterns were collected with a Bruker D8 Focus diffractometer powered at $40 \mathrm{KV}$ and $40 \mathrm{~mA}$ for $\mathrm{Cu} \mathrm{K \alpha}(\lambda=1.5406 \AA)$. Thermogravimetric measurements were performed from room temperature to $800{ }^{\circ} \mathrm{C}$ on crystalline samples using a SII TG/DTA7300 apparatus at a heating rate of $10{ }^{\circ} \mathrm{C} / \mathrm{min}$. UV-visible (UV-vis) spectra were recorded at room temperature on a PerkinElmer Lambda 900 UV/vis/NIR spectrophotometer equipped with an integrating sphere in the wavelength range of $200-1200 \mathrm{~nm} . \mathrm{BaSO}_{4}$ plates were used as reference (100\% reflection), on which the finely ground power of the sample was coated. Simulated patterns were produced using the Mercurey 3.1 software and single-crystal reflection diffraction data. ESR spectra were recorded on a Bruker ER-420 spectrometer with a $100 \mathrm{kHz}$ magnetic field in $\mathrm{X}$ band at room temperature.

$\mathrm{Zn}\left(\mathrm{NO}_{3}\right)_{2} \cdot 6 \mathrm{H}_{2} \mathrm{O} \quad(99.5 \%$, Sinopharm Chemical Reagent Co., Ltd) and N,N-dimethylformamide (DMF, 99.5\%, Sinopharm Chemical Reagent Co., Ltd) used for synthetic preparations were used as received unless otherwise noted. DMF used for electrochemical measurements was dried using a glass drying column fitted with $\mathrm{Al}_{2} \mathrm{O}_{3}$. Tetra-n-butylammonium hexafluorophosphate (98\%, Aladdin) was recrystallized from ethanol and dried in vacuo before use. Fluorine-doped tin oxide 
(FTO)-coated glass slides were cleaned by washing sequentially with distilled water, acetone, and hot ethanol. SEM micrographs were obtained with a SU-70 microscope at $5 \mathrm{kV}$. A CHI 660E Electrochemical workstation was used for cyclic voltammetry measurments. All electrochemical measurements was carried out in sealed electrochemical cells under a flow of nitrogen.

\section{Single-crystal X-ray diffraction}

The diffraction data of NBU-3 were collected on a Bruker Apex II CCD area-detector diffractometer (Mo $\mathrm{K} \alpha, \lambda=0.71073 \AA$ ). Absorption correction was applied by using multiscan program SADABS. The structure was solved with direct methods and refined with a full-matrix least-squares technique with the SHELXTL program package. Anisotropic thermal parameters were applied to all non-hydrogen atoms of NBU-3 . The positions of $\mathrm{H}$ atoms were generated geometrically, assigned isotropic thermal parameters, and allowed to ride on their parent carbon atoms before the final cycle of refinement. 


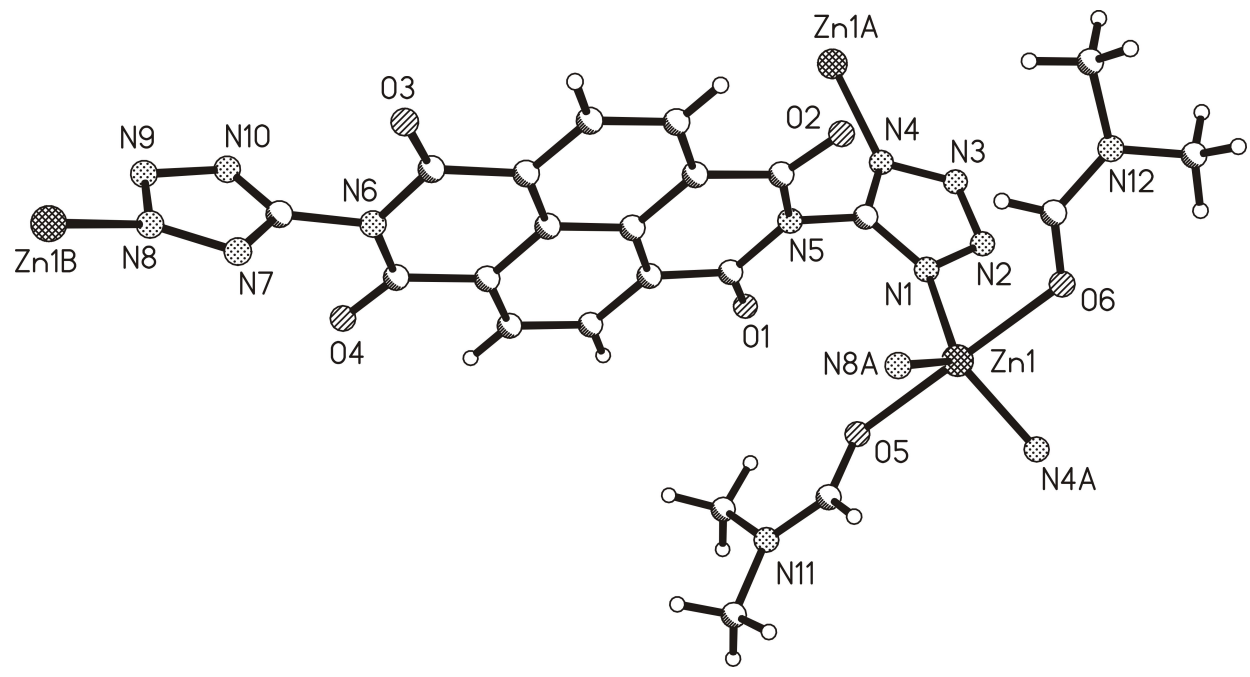

Figure S1. The asymmetric unit of NBU-3.

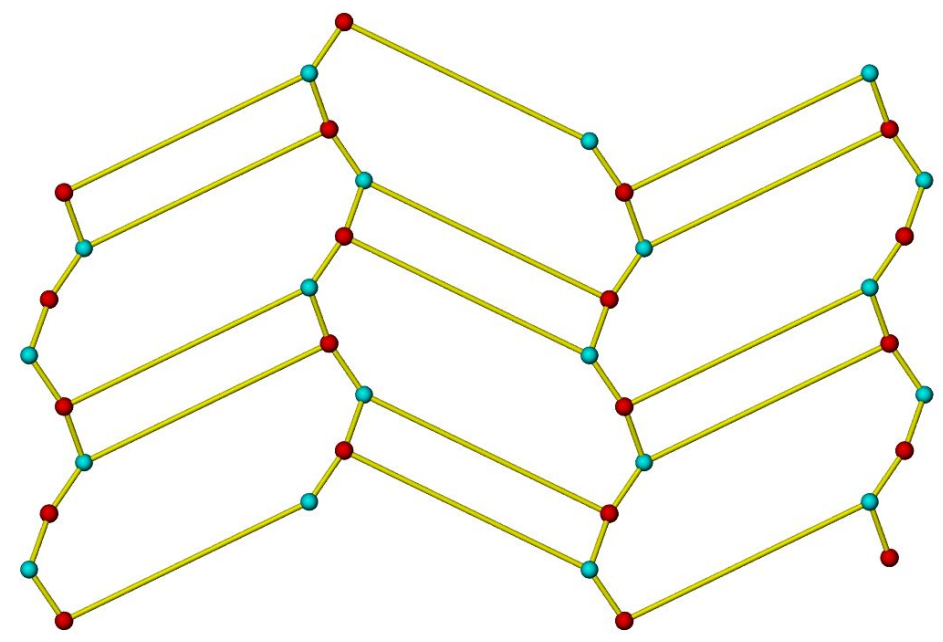

Figure S2. The 3-connected net of NBU-3. 


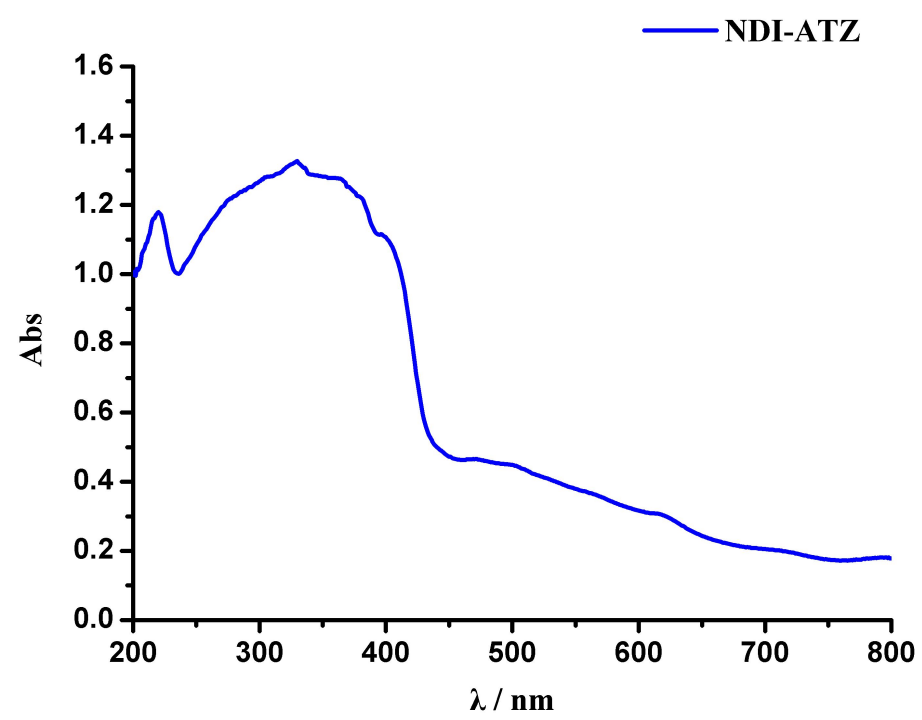

Figure S3. The UV/Vis spectra of ligand NDI-ATZ.

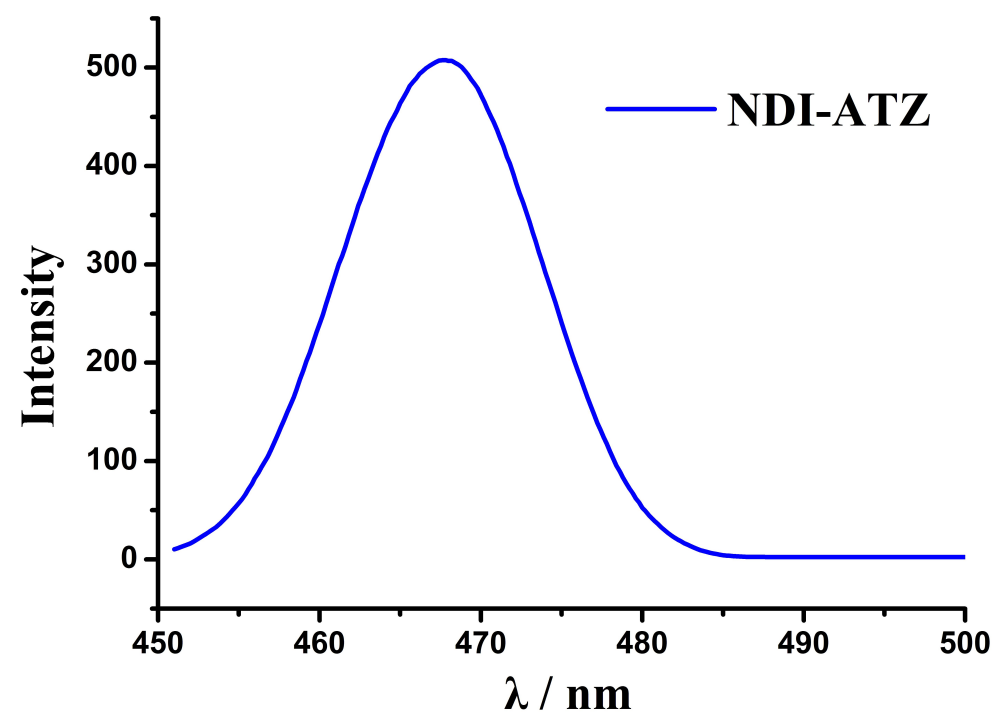

Figure S4. The emission spectra of NDI-ATZ . 


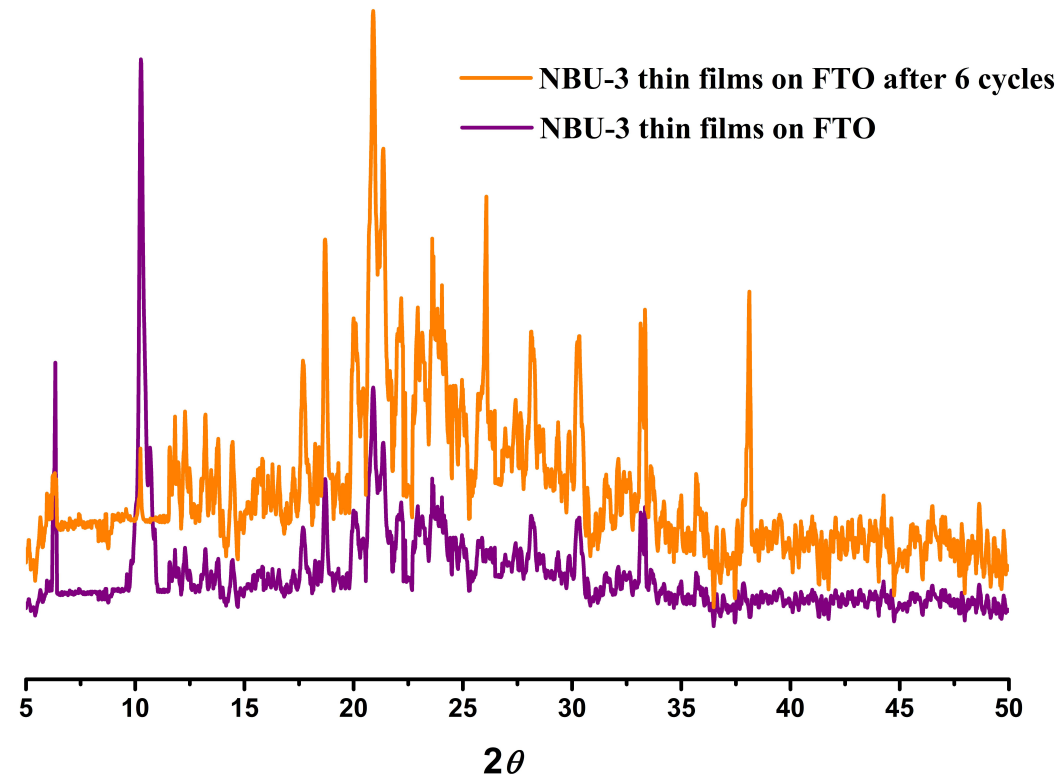

Figure S5. PXRD patterns of NBU-3 thin films on FTO after 6 cycles.

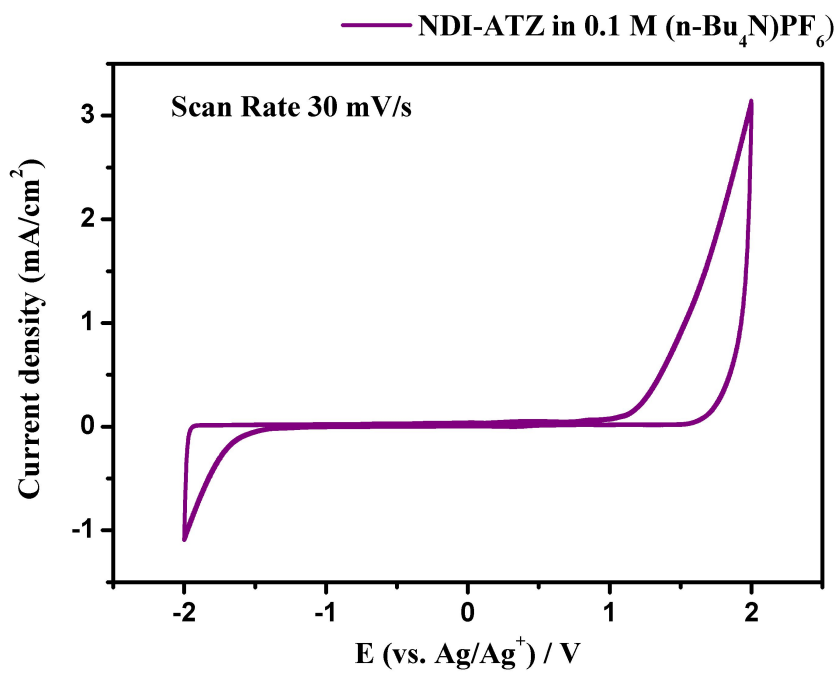

Figure S6. Cyclic voltammograms of the free ligand NDI-ATZ in DMF solution containing $0.1 \mathrm{M}\left[(\mathrm{n}-\mathrm{Bu})_{4} \mathrm{~N}\right] \mathrm{PF}_{6}$ at a scan rate of $30 \mathrm{mV} / \mathrm{s}$. 